\title{
Qaalluu, Smith and Metal: Traditional Conflict Resolution Mechanisms in the Medium of Metals among the Oromo of Northeast Wollega, Ethiopia
}

\author{
Temesgen Burka*
}

\begin{abstract}
The introduction of metals, particularly iron, has always been seen as an important stage of socio-cultural, economic, and political departure of human development. Nevertheless, since its appearance in the form of utilitarian or armaments, iron has occupied an ambiguous position in any society. It has played both the role of production by increasing fertility or prosperity, and destruction by furnishing the process of or terminating life. This ambivalent position of the material is also evident in the position of the workers in their respective societies. Consequently, its workers (the tumtuu) are both feared and respected. This ambiguous position/role of the material and the artisans has long attracted heated debates amongst archaeometallurgists. Although the double roles of iron tools among the Oromo traditional believers in Wollega can never escape such debates, engagement in such a debate is beyond the scope of this article. This article, however, departs from the search for the destinations of iron tools once they left the production sites in the operational sequences i.e. traditional ritual site of the Qaalluu. The data for this discussion have emerged from my current ethnoarchaeometallurgical research in northeast Wollega, which aims to documenting different destination of iron/metal products after they left the cottage of the smiths. This article attempts to draw on the secular meaning of metal tools in order to attain the symbolic significance derived from it. Utilizing the data from traditional spiritual sites in northeast Wollega (Butaa Nadoo and Sagro Guddina), the article outlines the peaceful resolution of various forms of conflicts at the traditional ritual sites in the medium of metal tools or by invoking their symbolic value.
\end{abstract}

Key words: Oromo, Wollega, Qalluu, Siida, Sibila Gurracha, conflict resolution

\footnotetext{
* Lecturer, Department of Archaeology and Heritage Management, Addis Ababa University
} 


\section{Introduction}

Ethiopian ancient metallurgical history is far from well documented (Burka 2006, 2008, 2009, 2010). However, passing remarks from archaeological data in the north of the Horn of Africa were made on the advanced metal production since about the middle of the first millennium BC (De Contenson 1981; Phillipson 1977; Todd 1985). I have elsewhere argued that much of the ancient cultural developments (e.g. obelisks, rock-hewn churches, refined megaliths etc.,) in different parts of the Ethiopian region could not have been possible without the use of metal tools (Burka 2006, 2008). In fact, my argument is cued by one of the previous works by such authorities like David Phillipson (1977) at Gobedra rock shelter and may not be taken for granted as causative to each other. Phillipson's excavations at Gobedra have produced significant metallurgical signatures - the site that is close to the major quarry area for Axumite stele production.

Metal tools must have served different areas of human life in the form of bush clearing, farming, curving cultural objects (stele, monuments, etc,) out of blocks of stones. The introduction of metals is believed to have finally resulted in population increase and the rise and development of complex societies (De Barros 2000) because of efficient use of environmental resources. The roles of metals have not actually been limited to secular aspects of human life (Haaland 1985). It is interesting to note that the symbolic role of metal is cross-cultural. Probably this is connected with the panhuman belief that the first iron has been dropped from heaven (Burka 2006; Haaland et al 2002; Mcosh 1979). People might first have begun to utilize meteoric iron before they developed the technological expertise of exploiting terrestrial ones. This all put together with the ambivalent roles iron tools play have highly complicated the nature of the discussion connected with the trade.

In this paper, first I shall bring into light the regional role of Wollega with regard to providing the ground for reconstructing a history of metallurgy. This is only part of establishing a background for the current research output. In the second phase of the paper, I would introduce the traditional Oromo belief system (in Waaqaa) and the institution (Qaalluu) that governs this belief system in the medium of metal/iron objects. In this case, I would argue that there is at least indirect relationship between the Oromo God Waaqa, the intermediary Abba Muuda (Qaalluu) and the forging of metal iron (Burka 2006, 2008). Then, I would present some selected metal items from one of the Qalluu institutions (successors of Abba Muuda site), the Butaa Nadoo (and supportive data from Sagro Guddina) of highland northeastern Wollega, which are still used to symbolically resolve conflicts. In the medium of the ritual father (Qaalluu) and his Salgee assistants, the tools are providing service either as instruments of curse and blessings the ultimate objectives of which were to settle peacefully disputes that secular courts could not attain. Metal tools (e.g. spear points, axes, needles, hoes, etc) become sanctified 
when they are anointed with blood (of bull or cow) during annual ritual ceremony. Finally, I would attempt to reflect on the ritual role of the data from northeastern highlands of Wollega and the wider context of the ritual role of iron among various societies.

\section{Research Background}

This is part of my ethnoarchaeometallurgical study that I have initiated in northeast and southwest Wollega (Abee-Dongoroo and Aira-Gulliso distracts) in 2004. The project has included survey and documentation of former metallurgy activity areas, reconstruction of local metallurgical history by the help of elders and an ethnographic documentation of a reconstructed/reenacted iron smelting technology and its socio-cultural aspects (see Burka 2006, 2008). In addition, the project also included the analysis of meaning of metal tools in the hands of their various endusers.

In 2004, I met two former smelters, both close to 90 years old (one of them died in September 2007) who with their former apprentices agreed to demonstrate traditional smelting practices stopped over forty years ago (see Burka 2006). These were smiths (tumtuu) who in the later period, after about the Second World War, took over smelting when the buuftuu (smelters) decided to drop. This story is similar in both northeast and southwest Wollega (Abee-Dongoroo and AiraGulliso districts respectively). The peculiarity of Wollega iron metallurgy, in contrast to its neighbors (see Haaland 2004; Todd 1985), is also the presence of not only diverse technology but also separate occupational identities in terms of smithing and smelting (Burka 2006, 2008). Unlike in the Omo valley (see Haaland 2004; Haaland et al 2004) where the same person performs both activities, in Wollega iron smelting has been conducted by a separate social and occupational identity nicknamed buuftuu.

Wollega also provides a peculiar example where people of close lineages, inhabiting over $200 \mathrm{~km}$ apart as the crow flies, practice distinctly varied iron smelting technologies. In this case, whereas iron smelters in northeast Wollega (Abee-Dongoroo) developed an underground iron smelting technological apparatus (Burka 2006), in southwest Wollega, splendid furnace superstructure of female anthropomorphic feature was the technological type (Burka 2008). The underground furnace of northeast Wollega has not hitherto been documented in Ethiopia and the Horn as well as northeast Africa. For instance, although the artisans in Dime and Oska Dencha have common origin but inhabiting in separate ecological niche, they have adopted a similar technological apparatus with minor differences (see Haaland et al 2004; Todd 1985).

The Wollega example not only entices an argument that favors long period of experimentation for its technology that explains its diversity but also lends the 
reason for searching for the symbolic dimension of the trade. Given such peculiarities and rich history, I have agreed to cover the cost for reconstruction of past smelting involving the series of operational sequences-from nature to culture. Reenactment (Burka 2006) in the northeast by second generation smiths and reconstruction in the southwest by former smelters and participants (Burka 2008) were conducted in 2005 and 2007 respectively. It must be noted however, that reconstruction/reenactment was achieved after a series of data retrieval techniques (interviews that involved individual and group discussions) were employed in addition to observation and survey of activity sites.

In this procedure, the ethnoarchaeometallurgy of iron smelting could document the physical and the non-physical aspects of the trade (technology and the socio-cultural aspects). The depth of the research that could go for looking for the symbolic dimension of metallurgy was attained from ritual attributes observed during production processes as well as the myth of origin of metals and the claim by the tumtuu that they occupied high places in the Oromo Gada practices in the past. Some questions that popped up included: why is the Qaallu prescribing animals (e.g. goats) reared by the tumtuu for propitiation of angry spirits (e.g. ancestral)? What invisible connection could be discerned between the Qaalluu and the tumtuu? What roles do objects produced by the tumtuu play at the Qaalluu sites?

\section{Iron: Its myth of Origin and Rituality in Oromo}

In the last over two centuries, the Oromo society is highly exposed to different religions overshadowing its indigenous belief system. The major outside religions adopted by the Oromos of different localities are Islam and different denominations of Christianity. Despite the impinging roles of the new religions, the traditional belief system in the name of Waaqeffana, meaning belief in Waaqa/God (see Megerssa 1994) continued to dominate the various aspects of the society's life particularly in the countryside. One can also find the Oromo indigenous belief in syncretism with the aforementioned alien religions. The Oromo indigenous belief that is conducted by worshiping Waaqaa Gurraacha (lit. Black Waaqa) on the top of mountains, near water bodies and under the shades of selected trees such as Odaa needed no preacher or messenger but in the intermediary roles of the Qallu and Qallitti (male and female spiritual heads). Their roles include foretelling events, and as traditional doctors providing traditional medicines as well as serving as judges to resolve various forms of conflicts among the people under their domain.

The concern of this paper is the spiritual heads' or their sites role to resolve conflicts performing ritual courts. It is interesting here to note that the Qaalluu of Wollega employed metal tools to resolve conflicts at the ritual courts. However, 
one wonders about what is new regarding the role of metals in resolving conflicts. One further asks that metals in the form of weapons (ranging from spear points and axes to sophisticated war machineries) are used for resolving small scale or largescale conflicts. Such means of resolving conflicts involves the use of the destructive powers of metal tools. It is about the functional role of metals. What is peculiar about conflict resolution mechanisms in the medium of metal tools is the use of the symbolic impact of the objects (because the tools were anointed with blood or ritualized due to this) or by invoking their physical characteristics to settle disputes. The ritual heads invoke the symbolic power of metal tools (their sharpness, as well as their heavenly origin) to convince the wrong doers to abstain from crimes or convince the crime they could have committed in the day-to-day life. The material culture, through which the spiritual culture of the people is addressed, for this discussion, is documented from the ritual places of Butaa Nadoo and Sagroo Guddina practiced under the Siidaa (Fig.1), a secluded area where a number of stele are erected under a Podocarpus tree, an evergreen tree regarded as father of all plant species.

Although the purpose of this work is not about the steles, a highlight would help our understanding of the ritual place where metal objects are brought for resolving conflicts. In the event of a ritual ceremony concerning, for instance, an oath (to clear out differences), different metal objects are taken to the Siida for practicing the oath. Therefore, the place is highly revered and feared because the power of Waaqaa is believed to communicate here. In my present observation, I could see that two rounds of nine each stele in sum eighteen are erected surrounding the tree trunk. Two of the stele erected parallel to the entrance are shaped phallic (symbolizing male fertility) and some fibers are tied around the necks. In front of the phallic stele are situated one incense burner and a bottle for commonly serving mead (booka), also needed for ritual purpose such as blessing during marriage ceremonies, conflict resolution etc. Outside the enclosure, on both sides of the only single entrance are also erected two stele. However, since the purpose of this paper is not such topics, I would suggest that the stele of western Ethiopia (Wollega) call for further study. 


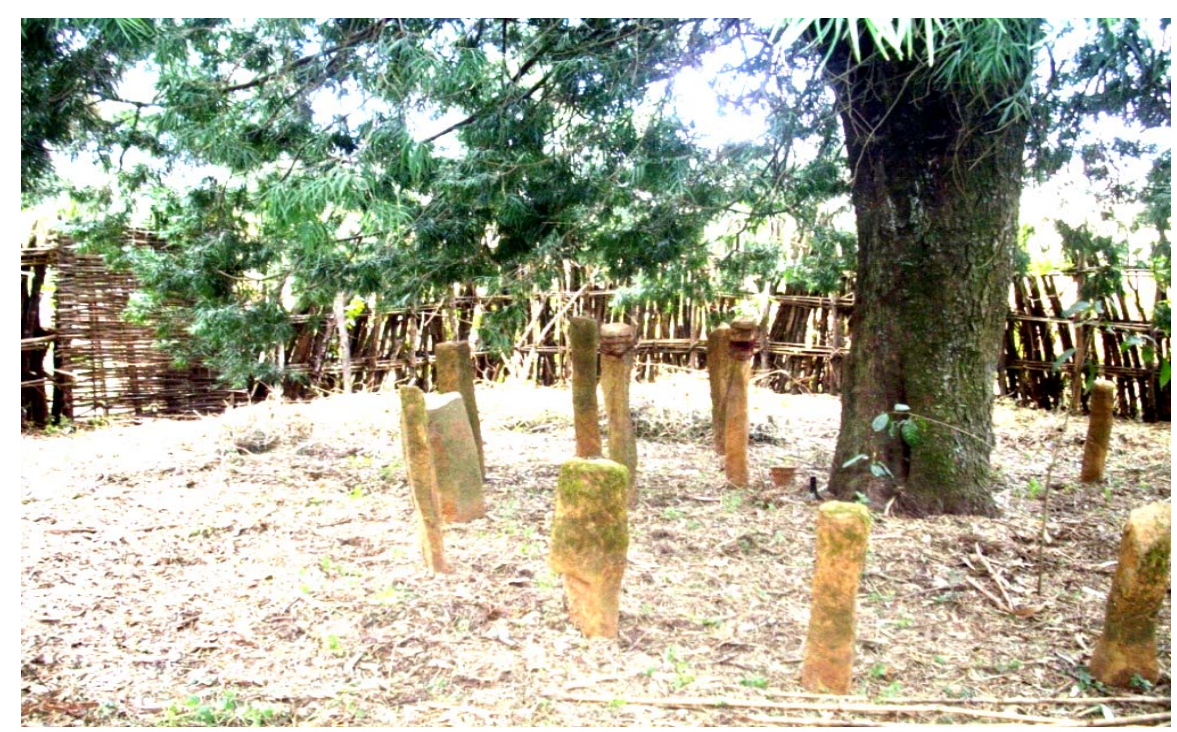

Fig.1: Sacred site called Siidaa in northeast Wollega-it is a site where ritual ceremonies including oath, curse and blessing takes place

Source: Temesgen Burka, 2009

\section{On the Myth of Origin of Metal}

There are at least two means of reconstructing the myth of the origin of metals in Oromo. The first is derived from the Oromo name given to metals particularly iron (sibiila/sibiila gurraacha) and the second is the relationship it holds with the traditional belief (Qaalluu) system of the people. As Megerssa and Kassam (1989) attempted to relate from the myth of the origin in Borana Oromo of southern Ethiopia of the first religious father, iron seems to have heavenly origin. According to them, it is a common view that the first religious father Abba Muuda (Burka 2006) who is believed to have descended from Waaqaa/God has been discovered in the jungles by the Waata hunters, the blessed marginal groups (see Kassam and Bashuna 2004). During this appearance, the Abba Muudaa (Qaalluu) is decorated with the black, white and red Oromo colors/flag as well as metal and shell objects. In this, it is argued that Abba Muuda has combined the symbolic relationship between maleness and femaleness in the medium of metal and shell objects (Burka 2008; Megerssa and Kassam 1989).

It has for some time now been suggested for seriously considering the connection between three interrelated elements in Oromo cultural manifestations namely-the black color of the cloth, the black color of the Oromo creator on the 
one hand with the black color of metal iron on the other (Burka 2006, 2008, 2009, 2010). The black part of the Oromo ritual cloth is a representative on earth of the heavenly Oromo black God, Waaqa Gurraacha. The clothes that the traditional ritual heads (Qaallu and Qallitti) dress during particularly ritual ceremonies and the ideology of which became a basis as symbol of the people's national color is rooted in this kind of legend. Accordingly, black is representing the unbounded powers of Waaqa, the white Waaqaa's promises in the form of fogs and the red one is symbolizing blood in the form of the sacrifices believers on earth make as a ritual response to what Waaqaa does for man. One of the metal decorations connected to the Abba Muuda and continued to be the case with his descendants, is a phallic object called Kallacha (Fig.2), an object symbolizing fertility, which the anointed father wears on his forehead (Burka 2009; Knutson 1967).

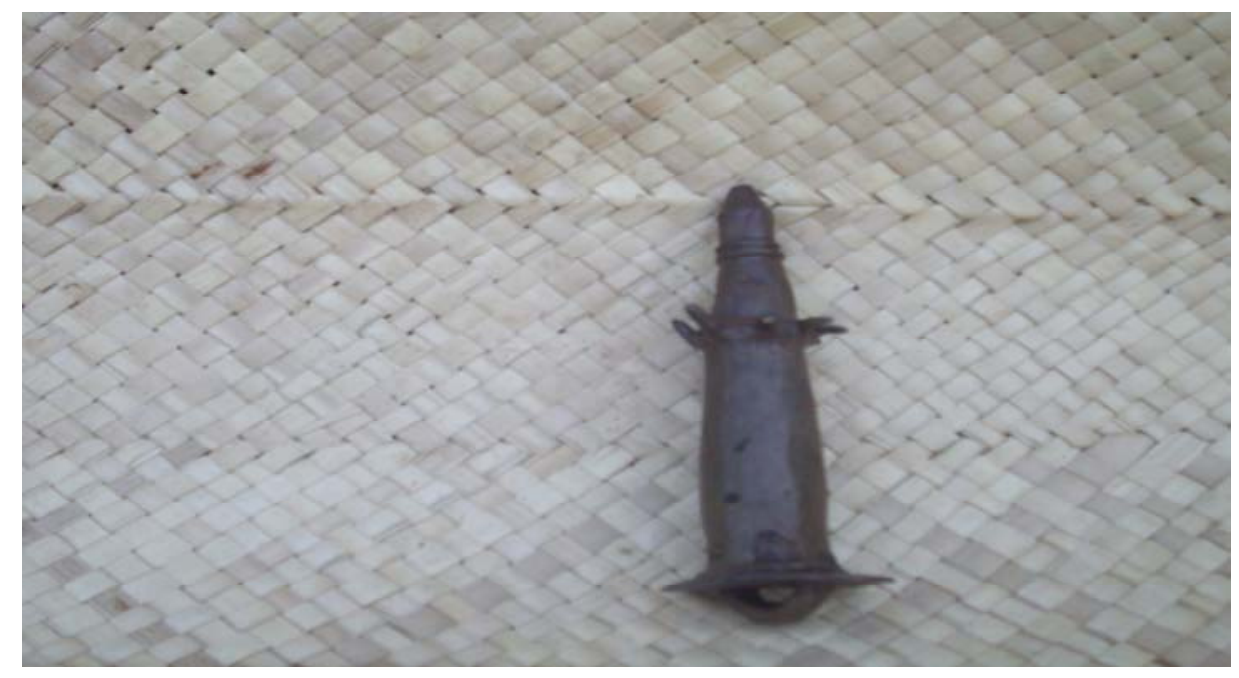

Fig.2: Kallacha (Phallic Object): Made of 'metal of Waaqaa', it is the possession of Butaa Nadoo religious site in northeast Wollega ${ }^{1}$

Source: Temesgen Burka, 2009

The phallic Kallacha is regarded sacred because its material is believed to have a heavenly origin (made by the first smith) that appears in the form of

\footnotetext{
${ }^{1}$ The first Kallacha is belived to have heavenly origin. It is instrument of law, being worn on the forehead of the traditional Oromo secular head.
} 
lightening to fertilize earth. It is always kept in a milk container (Okolee) made of plant fibers and is not exposed (a ritual object inside a ritually clean material, milk). Its material is bronze, copper, or iron. This object is instrument of fertility and blessings. It is feared and respected. It is produced in a 'clean' setting. According to the religious father at Butaa Nadoo who allowed us to photograph, Kallacha is not an instrument of curse but for blessings. It has eight smaller heads (nipples) and the main central one is shaped phallic. As a result, Kallacha has totally nine nipples, a symbolic number in Oromo representing salgan Borana, the Nine Borana-the ritually clean, chiefly and priestly class of the Oromo society (Burka 2009).

However, since the scope of this paper is confined to the role of the black metal, sibila gurracha, (iron) and the spiritual role of the object, the role of other ritual objects remains marginal. The Oromo term for iron is sibila gurraacha (Wainright 1942) since its origin is attributed to Waaqa Gurraacha. I have elsewhere argued that this naming is rooted in the universal belief that iron originated from sky, Waaqayyao (Burka 2006). Since the Oromo do not have primary vocabulary for blue, the color of sky and water is black (also called Waqaa's belly). Thus, there is plausible/ reasonable connection between the colors given both to the sky and to iron, hence the belief associated with the origin of the latter and the origin of its symbolic value. I have also discussed the significance of looking at iron production (particularly smelting) in light of the holistic Oromo cultural milieu (Burka 2006, 2008) in particular the relationship between iron production, agricultural fertility, and human procreation. The focus of this paper is on the symbolic role of metal tools at the ritual sites-roles detached from their primary (functional). In the following, I would present some metal objects, a whip and a matchbox (fire maker wood) that are used together to deal with various social problems (Fig.3).

\section{Metals as Instruments of Conflict Resolution}

To begin with, these objects include such metals like bush knife, double edge knife, horse harness, foot chain, three-point grill, two-point spearhead, needles, a spear with two rows of twisted ends, a plough share (hoe), an axe, pincer, broken whip, a Bokkuu (a bell-like metal with handle sound maker inside the main body), a pincer and Qonyee (plough harness). In this presentation, I am obliged to use the Oromo terminologies of the objects since the local names also connote the special meanings they convey during the conflict resolution court-like procedures. The court-like conflict resolution procedure takes place at the traditional ritual sites. In the past, the Oromo had its own indigenous political system whereby the people dealt with their affairs and solved various problems with the centrality the system, religious figures and their objects. I am of the conviction that a great deal of 
cultural information can be obtained through readings of the objects according to their new dimension as opposed to their primary roles. In the following, I shall describe the secular roles some selected metal objects provide for invoking their symbolic significance.

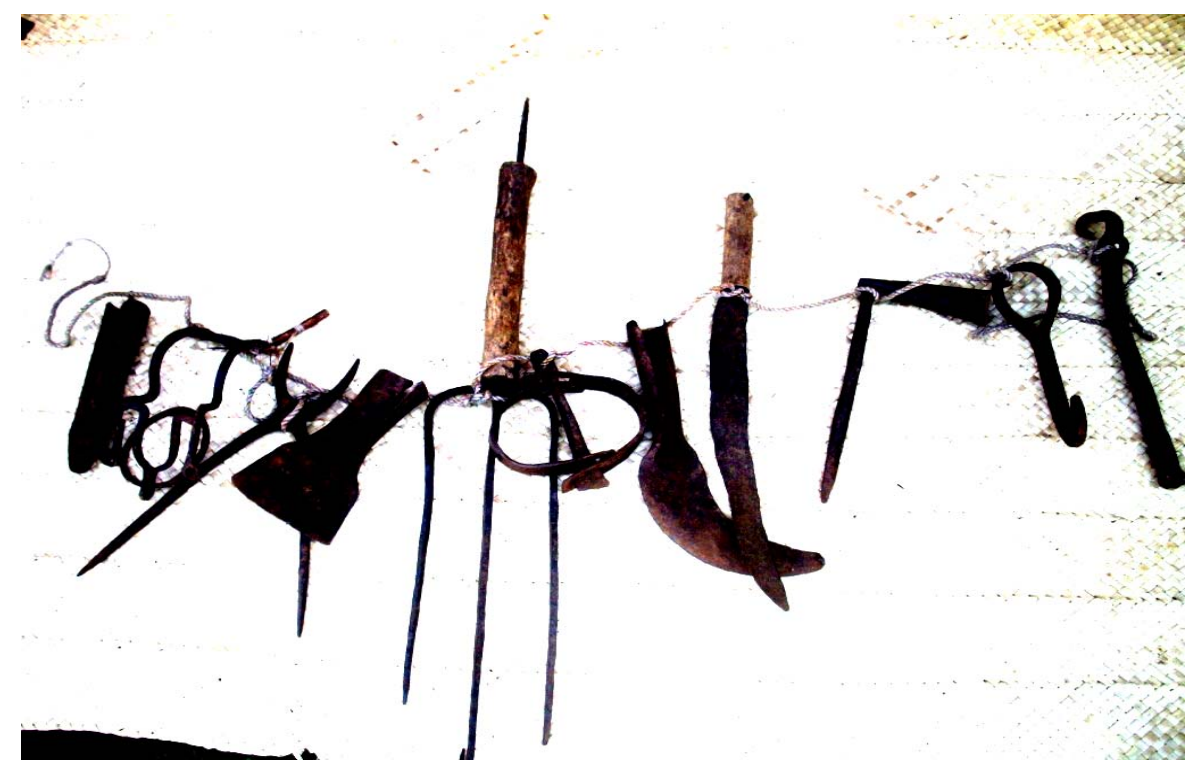

Fig.3. Some objects used for oath at Butaa Nadoo ritual center

Source: Temesgen Burka, 2009

\section{Qottuu (hoe, ploughshare) and Qonyee}

One of the subsets of the packages of the objects of curse (Oath) is an hoe (ploughshare) (Fig. 4a) and the other is Qonyee (fig. 4b). Their primary (secular) function is very clear. Whereas the first is used for splitting the ground, the latter serves the role of harnessing together (Fig. 4c) the farming components of the plough. It is to cultivate land. It penetrates the mother earth and prepares the farm for cropping. It is an instrument of agricultural production. The owner of the hoe is able to feed himself or members of his family. Furthermore, if the hoe is forged from metal of Waaqaa (metal created by lightening), it is believed to secure fertility and prosperity.

This primary characteristic of the tool is taken to a secondary level in a sense of object of punishment (after it is dipped into the ritual blood). Blood is a transformative agent (see Burka 2009). Under the condition when the wronged and the wrong doer present their cases in front of the ritual court, this material is 
brought to the scene of negotiations. The ritual father and his subordinates (the Salgee also carrying their blood anointed spear points) use this batch of object for ruling over the matter and as a truth finder. This becomes imperative under the situation where the accused denies the alleged crime. Then the ritual heads ask if he would like to take an oath in the medium of the object. If he agrees, then he has to pass through all objects in the ritual package (see Fig.3) and be freed.

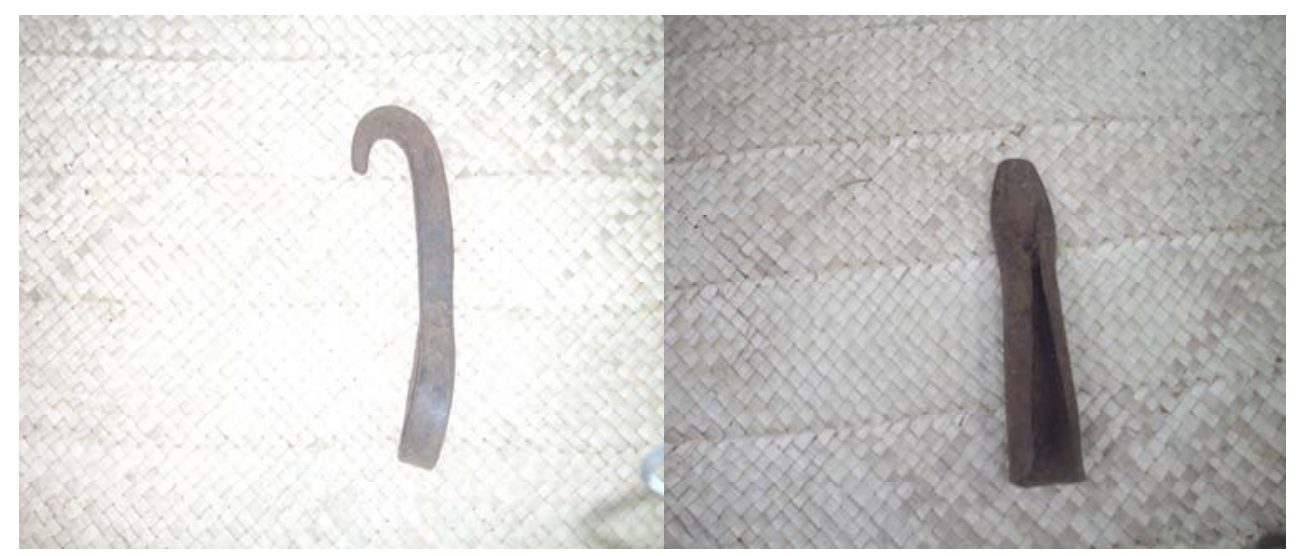

4(a) $4(b)$

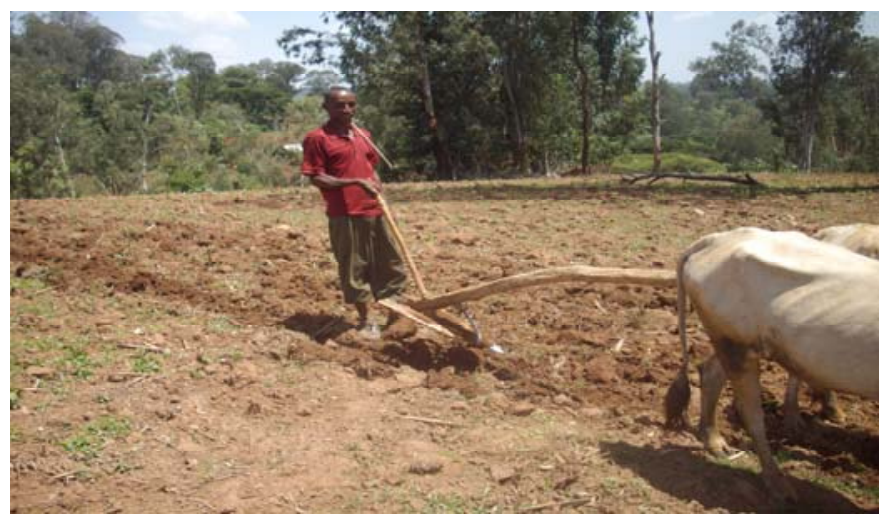

$4(c)$

Fig.4 (a-c): The plough- ploughshare (a), the metal harness (b) and the tools in their farming context (c) in southwestern Wollega, near old iron mining site.

Source: Temesgen Burka, 2009 
The accused would echo after the head of the Shanee/Salgee (the nine advisory body of the religious father-the Qaalluu). According to the spiritual fathers Obbo Abdisa and Waqtolee, the defendant would call all spells that the symbolic power of the plough (of Waaqaa) and the harness bring onto himself. He accepts the chilling, penetrating, and gripping invisible heavenly powers of Qottuu and Qonyee (in the form of aches) on himself, on members of his family and his property (notably the livestock). Literally, he would say 'if I did this or that may the sharp plough-end of Waaqaa penetrate my body...kids and ... family; may the strong grips of the Qonyee (of Waaqaa) make me immobile (in the form of crippling illness), paralyze me; may my farmstead remain uncultivated, may I not have any produce ...the fruits of Qottuu and Qonyee.. may I, my kids, and family miss the fruits of this object and starve to death....' The oath does not stop here as far as the accused did not give in; it continues in the medium of other ritualized metal objects.

\section{Samsa, luugama (metal horse harness)}

The significance of saamsaa is clear in relation to its functional role - to control horses and mules. Since the harness is put between the jaws, (Fig. 5a) the animal is not able to graze or chew. It also prohibits the animal from making noises. It is generally an instrument of suppression and control of the wild (evil) behaviors. Symbolically this object serves to harness wickedness and directs to righteousness.

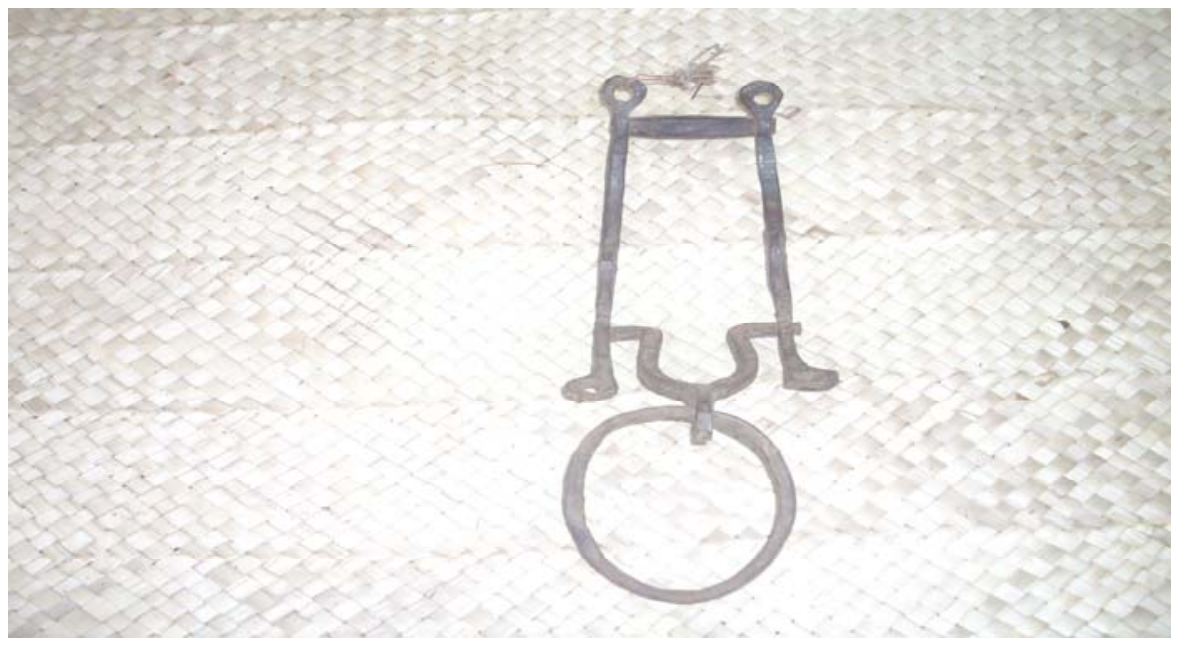

Fig. 5: A metal harness of a horse or mule

Source: Temesgen Burka, 2009 
In a similar procedure to the above, the alleged wrong doer begins to call curses (invoked from the harness) on himself, family and his property. Some of the contents of the oath include that he would say may saamsaa of Waaqaa (the spiritual saamsaa) shut my mouth, the mouth of my family and my cattle; may I, or my family not say a word again if I did what I am accused of, may the muffling power of saamsaa of Waaqaa bring its spells on me. Then the Salgee (who are also empowered with their sacred spear points) continue to bring in more objects that the defendant would cross over or touch and call all misfortunes on himself.

\section{Mutaa (needle)}

Under normal circumstances, mutaa performs different functional roles such as sewing clothes or baskets and unmaking woman's hair (Fig.6). It is also used to take out thorns or other sharp points that pierced into ones footstep. In other areas, it is also used as a marriage gift in a ceremony known as suuqqata, (symbolizing male hood) where some ritual grasses and other objects are inserted to the hair of the would be bride together with mutaa. Therefore, its socio-economic (e.g. sewing) and cultural (e.g. dowry) value is highly diverse (Burka 2010). In other ritual contexts, this object with other similar metal tools is used to protect beasts from attacking domestic animals by inserting it in the fireplace (Burka 2006, 2009). In this case, mutaa plays both secular and ritual roles. Nevertheless, its symbolic significance is derived from its sharp-ends' piercing power.

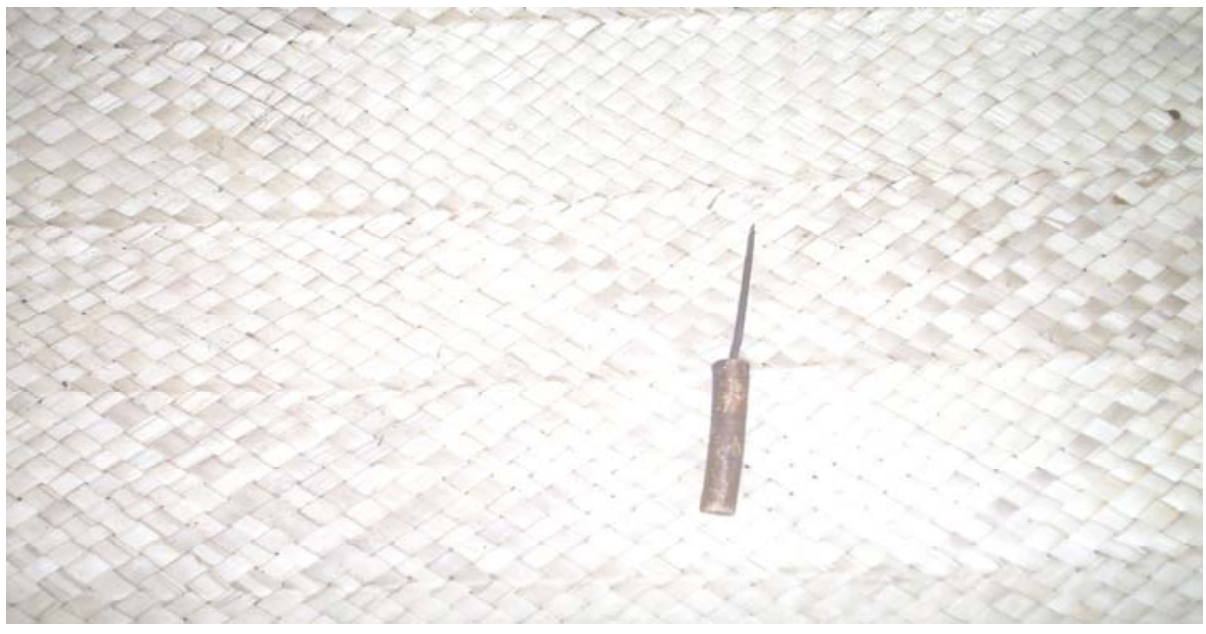

Fig.5: Mutaa, one of the displays of the ritual sites for conflict resolution 
Despite such practical and the symbolically positive roles that it plays, the object is also used as an instrument of curse and destruction or punishment. Sometimes, compatriots might betray each other on their common projects. There is time when the wronged could not bring the wrong doer to the spiritual site. Then the role of mutaa is invoked to resolve the dispute. The wronged would go to the spiritual site, discuss with the holders and as advised call on nuisances on the wrong doer inserting the needle near the revered site, the Siidaa (Fig.1).

In the same token, the symbolic power of mutaa is used to convince the wrong doer in the face-to-face dialogue. The accused would similarly say may the sharpness of this needle pierce deep into my heart and tear it apart, may its pains be felt deep inside me etc; and then the Qaalluu and his councilors would proceed with the rest of tools.

\section{Qabduu (pincer, tweezers)}

It is clear that Qabduu/ pincer is used for grasping objects which are not appropriate otherwise. It is not its English meaning that enables us understand other dimensions than the practical uses (Fig.6). Its Oromo term provides us with insight into a symbolic meaning of the tool. For instance, the phrase Qabaa Waaqaa literally means Waaqaa's grasps connotes supernatural infliction in the form of various illnesses. The understanding is that all objects have their origins with Waaqaa or sanctified with blood anointment during ritual ceremony.

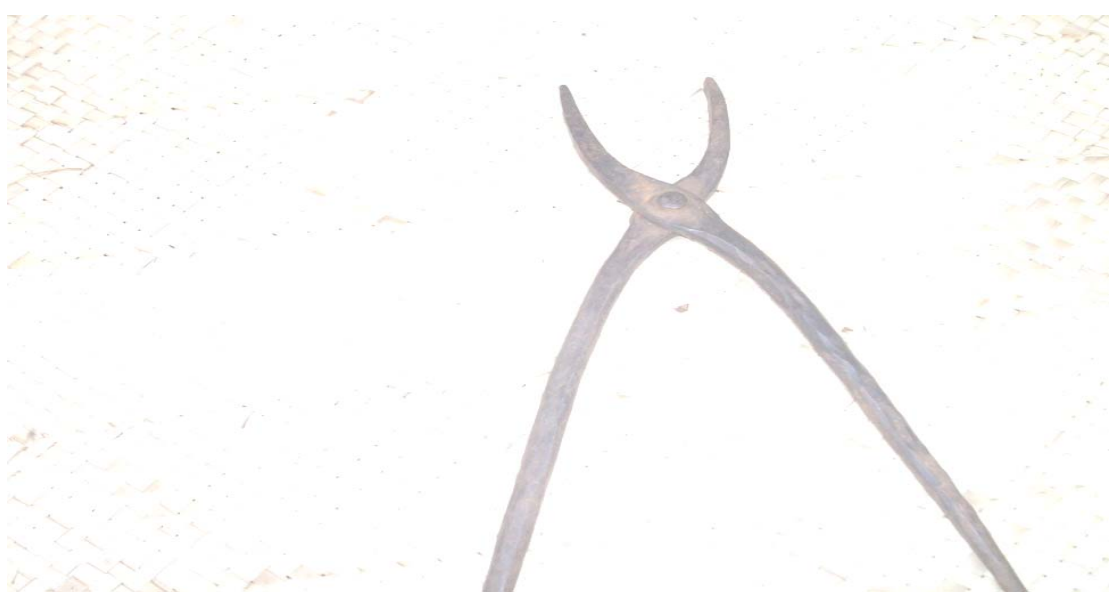

Fig.6: Qabdduu (pincer) is among the major components of the smith's tools and particularly used to handle hot objects 
It is, therefore, such symbolic aspects of the object, which is used during oath or curse. The person symbolizes this object with Waaqaa's infliction and calls on himself, his family and property the various forms of punishment if he really wronged his companion.

\section{Gubaa, waxalee (grill)}

There is a peculiar meat roasting culture in the Oromo society. In Wollega countryside meat is roasted on an open fire by thinning out the meat into longer sizes. In most cases, a wooden bar is used to hang over the flame of the fire and protecting it from direct touch with the ash. Nevertheless, in houses of nobles or rich peasants iron (metal) grill is used for this purpose replacing a wooden one (Fig.7).

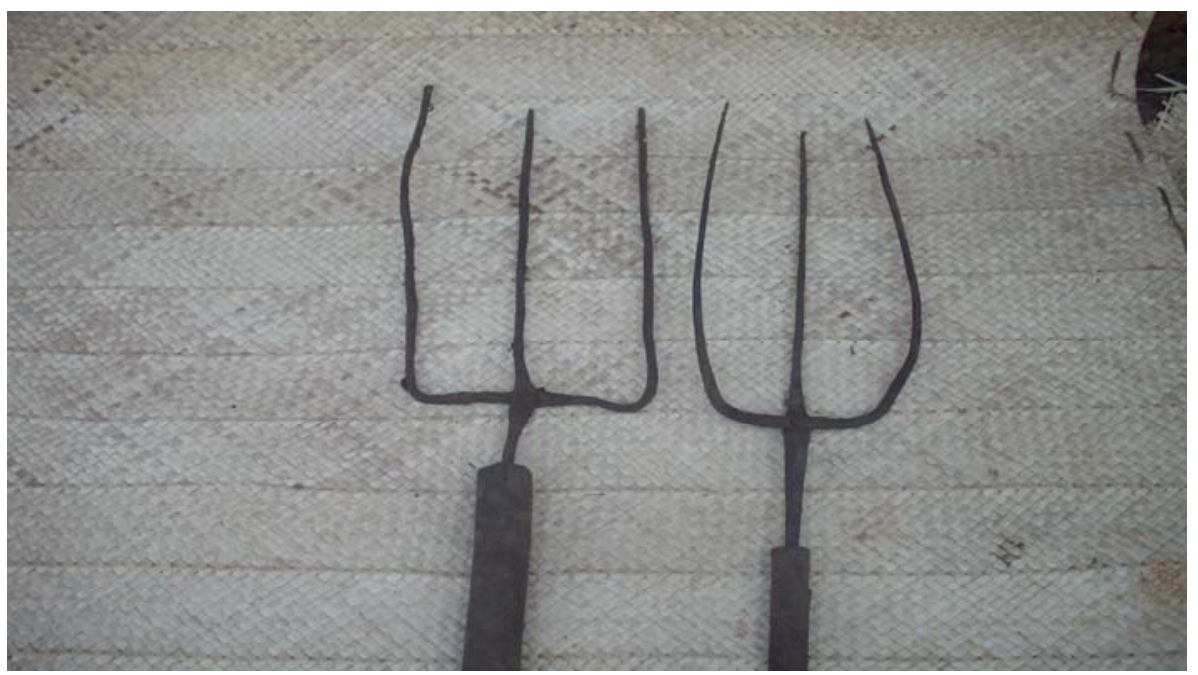

Fig.7: Waxalee or gubaa is also in the components of the belongings of the ritual heads

It is called gubaa or waxalee (both literally indicate the impact of heat or fire or its burning sensation) in Oromo language. It is therefore the burning role or its being exposed to the fire that is taken to the context of curse or oath. In this context, the wrong doer is expected to spell that the heats of the grill of Waaqaa or Butaa Naadoo or Sagroo Qaallichaa, for example, burns him, burns down his beloved ones and his property. Such spells are highly feared to happen if one does wrongs and still calls spells on him. 
There is another advantage of gubaa. In the countryside where cattle are marked from clan member to other members, it is customary to burn sides of livestock according to clan markers. The same material is also used to treat some swellings on animals' bodies by burning around the swollen area.

\section{Eeboo Qoraatti, Xeer-guuree and Eeboo Qar-lamaa}

Both are very special types of spears. The former is a type of spear point that is used for stabbing while the latter is not in common use. According to the tradition, the fighter keeps the thorny spear in his hands. He does not throw it since there are other throwing spears. As a result, this spear (the harpoon) is designed specifically to inflict an in and out damage. In this case (Fig.10) on both sides of the spearhead, close to the socket, a number of sharp points are added. These points are used to drag out inside organs after stabbing. The two-headed spear is not commonly used. It is only found in such ritual areas and is symbolical.

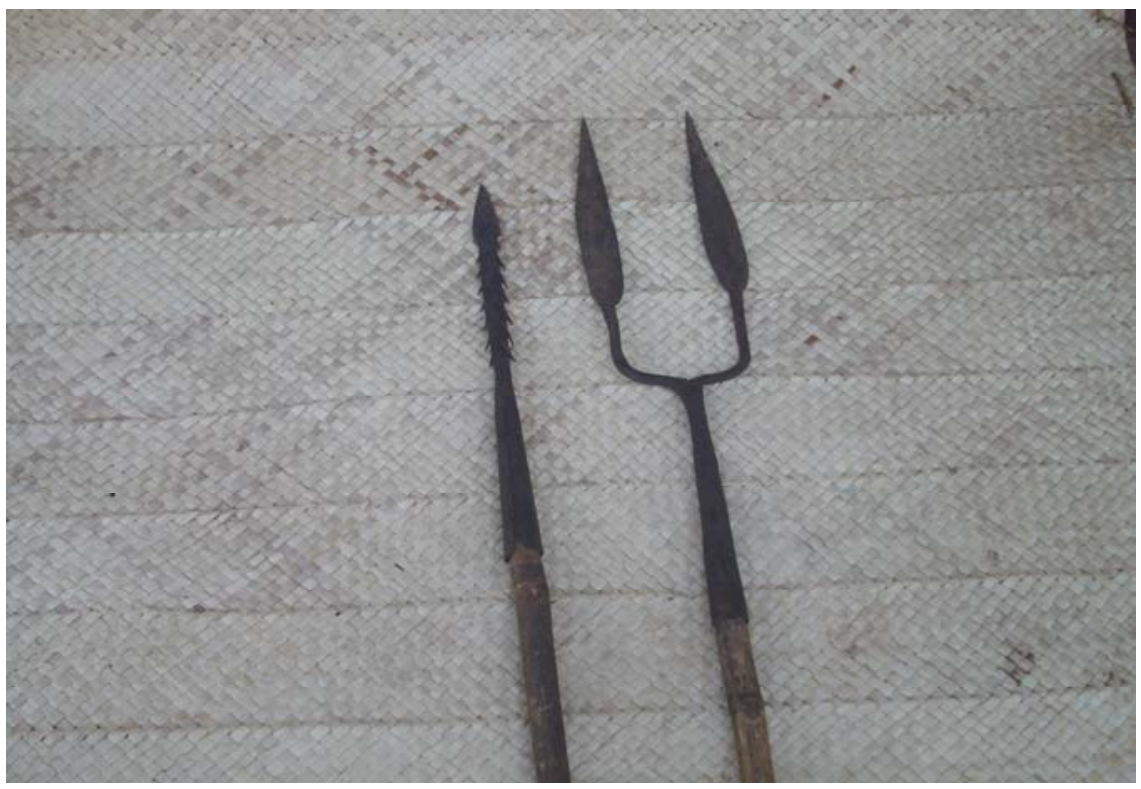

Fig.8: Spear points, Eeboo Qoraatti (harpoon) and Eeboo qara lamaa (double heads)

These two are very special types of spears. The former (Fig.8 left) is a harpoon-like spear point that is used for stabbing while the latter is not in any combat use and is a symbolical weapon. However, the harm that a double-headed spear creates is also believed to be heavy. As a result, symbolically the two headed 
spear is also great. Therefore, during an oath (or when reconciliation through oath is made) the persons are expected to call on themselves the consequences (physical and spiritual) the sharpness of such weapons brings on themselves and their close families and properties. The whole idea emanates from the belief that such weapons exist in both earthily (observable) and heavenly (invisible) worlds. The earthly ones seem to be the copy of the heavenly original ones at the domain of Waaqa Gurraacha.

Therefore, in the ritual context it is the 'invisible' severity of the harpoons or the double heads that is made use of. The accused person would say may the thorn of this spear turn my inside out; may my body feel the thorny pains that this weapon inflicts; may the thorn of Waaqaa tear me all around; may the double head spears of Waaqaa inflict wounds on me and my family etc. The ritual heads (Qaalluu) claim it is so rare that people would get courage to take the oath through the tools and weapons unless they did not do wrong.

\section{Reflection on the Spiritual Role of Metals}

My discussion regarding the spirituality of metal (iron) tools is rooted in the myth of the origin of the material itself and the panhuman characteristics connected with it. Like in most societies, among the Oromo, iron is believed to have originated from the sky (Waaqayyo). The myth of the origin of the first smith, Hinno (see Burka 2009) adds powers to the spiritual significance of metal. According to the myth of origin of the first smith (Hinno), Waaqaa made him forge the first Kallacha from the metal of Waaqaa. In addition, Hinno was given a spiritual (prophecy) power to head the people. As we have already discussed in the introductory part, it is panhuman to believe that metal primarily originated from the sky. In this regard, the Oromo belief is not exceptional. What is exceptional is that the knowledge of smithing is also a heavenly one. The other exception about the Oromo is that the knowledge of smithing and the spiritual power of the Qaalluu are contained in one person. It is from such myth that we can be able to draw a plausible conclusion that the reason for the use of metals at the Qaalluu site is part of an invocation of heavenly powers of the material.

In this paper, an attempt is to direct our attention first to the connection between the myth of origin of metals and the traditional belief system that legitimates the secular rule and the life of most people. The second point that I would like to underline is the need to identify one of the various destinations of metal products as soon as they left the smith's forge. In addition, it is an attempt to establish the close relationship between metal production sites and the Oromo traditional sacred (belief) areas. I have previously argued (Burka 2006) that it is possible to draw some level of conclusion that a connection existed between the sacredness of mining sites and the belief that surrounds the sacred origin of the 
material. I have also related the fact that iron slag and an axe are buried in the basement of symbolic door (back door) in the countryside houses meant to protect spells is an example of its ritual foundation.

Finally, it is to emphasize the fact that metals possess extraordinary roles in resolving social problems. I believe that the perspective that we need to develop is a nuisance and is not a common one. This means that metal weapons are seen as if they are used to solve problems in the form of efficient combat tools only. In other words, weapons made of metals are known to resolve violence in a similar manner. However, the data from Wollega has sufficiently shown that metal tools/weapons possess symbolically powerful meaning to resolve conflicts in a peaceful manner. In this regard, we need to conceptualize the need to address such indigenous knowledge of conflicting resolution mechanisms for realization of a stable society. The mechanism we have observed in Wollega has shown that ritual courts could attain the ones the secular courts could not. On the other hand, since the paper is part of an ongoing research, I hope that more culturally embedded insights would be made available in the future through integrated research endeavors.

\section{Acknowledgements}

I am very much grateful first to the indigenous Qaalluu heads (Obbo Abdiisaa and Oboo Waqtolee) who allowed me to have access to the ritual objects and procedures of conflict resolution. I should also thank provincial cultural experts in East Wollega, Obbo Belay Shiferaw and Obbo Chernet Waqweyya for creating favorable contact with the ritual sites and accompanying me to the field. Lastly, the constructive comments of the two anonymous reviewers are well taken.

\section{References}

Burka, Temesgen. 2006. "Iron Smelting in Wollega, Ethiopia: An Ethnoarchaeological Study”. MA Thesis, University of Bergen, Norway. 2008. "The Socio-cultural aspects of furnace shape, decorations: Iron smelting activities among the Oromo of West Wollega, Ethiopia” Nyame Akuma, 69:1-9. . 2009. "Why the Tumtuu are Not Marginalized: New Perspectives on thePositions of the Smiths in Western Ethiopia, Wollega" Nyame Akuma, 72:12- 20.

. 2010. "Cultural Aspects of Metallurgy in Ethiopia: the case of Iron production in Wollega” In Claudio Giardino (ed.) Archaemetallurgia dalla conoscerza alla fruizione, 355 Congedo editor, Galatina (Lecce). 
Contenson, de H. 1981. "Pre-Aksumite culture” in Mokhtar, G. (ed.) General History of Africa II: ancient civilizations of Africa. University of California Press. Berkeley. PP.341- 361.

De Barros, Phillip. 2000. "Iron Metallurgy: Sociocultural context ». In Bisson, M, Childs, T, De Barros, P, and Holl, A. (eds.) Ancient African Metallurgy: The Socio-cultural Context. New York: Altamira Press. 147-199.

Fattovich, R. 2009. “Reconsidering Yeha, c. 800-400 BC” African Archaeological Review, 26 (4): 275- 290.

Haaland, R. 1985. "Iron production, its socio-cultural context and ecological Implications" in Haaland, R., and Shinnie, P. (eds.) African Iron Working:Ancient and Traditional. Norwegian University Press. New York. 2004. "Iron smelting - A vanishing tradition: Ethnographic Study of this craft in Southwest Ethiopia” Journal of African Archeology 2 (1). . 2007. "Say it in Iron: Symbols of Transformation and Reproduction in the Euopean Iron Age” Current Swedish Archaeology, 15:1-20.

Haaland, G. and Haaland, R. 2007. "God of war, worldly ruler, and craft specialists in the Meroitic Kingdom of Sudan: Inferring social identity from material remains.” Journal of Social Archaeology 7(3):372-392.

Haaland, G., Haaland, R., and Dea D. 2004. "Smelting Iron: Caste and its symbolism in South- Western Ethiopia” in T. Insoll (ed.), Belief in the past: The Proceedings of the Manchester Conference on Archaeology and Religion.

Kassam, A. and Bushana, Ali Balla. 2004. Marginalization of the Waata Oromo Hunter-Gatherers of Kenya: Insider and outsider perspectives. Africa: Journal of the International African Institute, 74 (2):194-216.

Kassam, A. and Megerssa, G. 1989. "Iron and Beads: Male and female symbols of Creation: A study of ornament among Booran Oromo” in Hodder, I. (Ed). The Meaning of Things. Material culture and symbolic expression. London, Unwin Hyman Ltd.

Knutson, K.E. 1967. Authority and Change: A study of the Kallu institution among the Macha Galla of Ethiopia. Gotenborg, Ethografiska Museot.

McCosh, F.W.J. 1979. "Traditional iron-working in central Africa with some references to the ritualistic and scientific aspects of the industry". Zambezia, VII (ii): 155-170.

Phillipson, D.W.1977. "The Excavation of Gobedra Rock Shelter, Axum: an early occurrence of cultivated finger millet in Northern Ethiopia.” Azania, XII. Journal of the British Institute in Eastern Africa.

. 2009. "The First Millennium BC in the Highlands of Northern Ethiopia and South-Central Eritrea: A Reassessment of Cultural and Political Development”. African Archaeological Review, 26 (4): 257-274. 
Todd, J. A. 1985. "Iron production by the Dimi of Ethiopia”. Haaland, R. and Shinnie, P. (eds.) African Iron Working: Ancient and Traditional. Norwegian University Press,

Wainwright, G.A. 1942. "Early Records of iron in Abyssinia.” Man. 42:84-88. 